\title{
Malignant eccrine acrospiroma with nodal and bone metastasis
}

\author{
Burhan Wani, Shiekh Aejaz Aziz, Mohmad Hussain Mir, Gull Mohammad Bhat, Abdul Rashid Lone
}

Department of Medical Oncology, Sher-i-Kashmir Institute of Medical Sciences, Srinagar 190011, Kashmir, India.

Correspondence to: Dr. Burhan Wani, Department of Medical Oncology, Sher-i-Kashmir Institute of Medical Sciences, Srinagar 190011, Kashmir, India. E-mail: burhan4187@gmail.com

\section{A B S T R A C T}

Acrospiromas are cutaneous tumors of sweat duct differentiation. Although various eccrine sweat gland tumours including benign acrospiroma are widely reviewed, malignant acrospiroma is rarely reported. Clinically, they resemble other cutaneous lesions and the primary treatment is wide local excision with or without lymph node dissection. The efficacy of adjuvant chemotherapy and radiation therapy requires further investigation.

Key words: Acrospiroma; metastasis; chemotherapy; radiotherapy

\section{INTRODUCTION}

Acrospiroma represents a group of benign ductal tumors of the eccrine sweat glands that sometimes are connected to the skin, ranging from solitary plaques to exophytic papules or dermal nodules. ${ }^{[1]}$ Malignant acrospiroma (Syn: malignant nodular/clear cell hidradenoma, malignant clear cell acrospiroma, clear cell eccrine carcinoma, primary mucoepidermoid cutaneous carcinoma) comprises a group of rare epidermal, juxta-epidermal, and dermal ductal carcinomas that may coexist with their benign counterparts and have the potential for regional lymph node and, very rarely, distant metastases. ${ }^{[2]}$ The primary treatment is wide local excision with or without lymph node dissection. ${ }^{[3]}$ We describe a case of a malignant acrospiroma involving inguinal region with metastases to inguinal lymph nodes and bones in a 37-year-old man despite initial wide local excision. Although various eccrine sweat gland tumors including benign acrospiroma have been widely reviewed, malignant acrospiroma is rarely reported and thus the literature on their response to chemotherapy is limited.

\section{CASE REPORT}

A 37-year-old man presented at our medical oncology outpatient department with complaints of a mass in the right inguinal region for over 1 year with no history of antecedent trauma. The mass gradually increased in size and was associated with mild discomfort. There was no skin ulceration or discharge. Examination revealed a rounded mass adherent to skin with diameter of $4 \mathrm{~cm}$ in

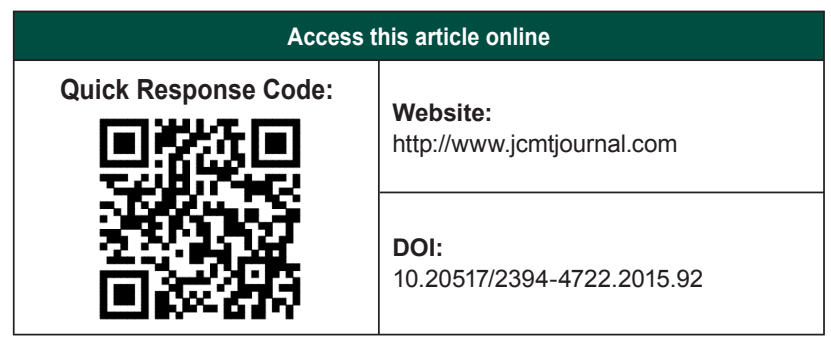

right inguinal region. The swelling was firm in consistency and mildly tender. There was another mass $2 \mathrm{~cm}$ below this measuring $3 \mathrm{~cm} \times 2 \mathrm{~cm}$, firm in consistency, mobile, non-tender with normal overlying skin, felt to be a lymph node clinically.

The patient was operated on and excision of the mass along with inguinal nodal dissection. Pathology revealed dermal appendage neoplasm (acrospiroma -- of hydra adenoma type), well-circumscribed, with mitotic figures $(<2 /$ hpf). No necrosis was seen. Nodal tissue showed metastasis from the same tumor [Figures 1 and 2]. The patient was put on regular follow up and no adjuvant chemo/radiotherapy was given in view of lack of clear benefits from either of these modalities.

However, patient was lost to follow up and presented 1 year later with swelling in same area. The swelling had appeared 4 months earlier and gradually increased in size, associated with mild discomfort. Examination revealed a firm, smooth swelling, not adherent to skin, round in shape with dimensions of $6 \mathrm{~cm} \times 5 \mathrm{~cm}$ in the right inguinal region.

Computed tomography (CT) with contrast of chest, abdomen and pelvis revealed a well-defined soft tissue density lesion in the right inguinal region, with minimal fat stranding. The lesion showed mild heterogenous enhancement [Figure 3].

This is an open access article distributed under the terms of the Creative Commons Attribution-NonCommercial-ShareAlike 3.0 License, which allows others to remix, tweak, and build upon the work non-commercially, as long as the author is credited and the new creations are licensed under the identical terms.

For reprints contact: service@oaepublish.com

How to cite this article: Wani B, Aziz SA, Mir MH, Bhat GM, Lone AR. Malignant eccrine acrospiroma with nodal and bone metastasis. J Cancer Metastasis Treat 2016;2:255-8.

Received: 18-12-2015; Accepted: 30-03-2016. 


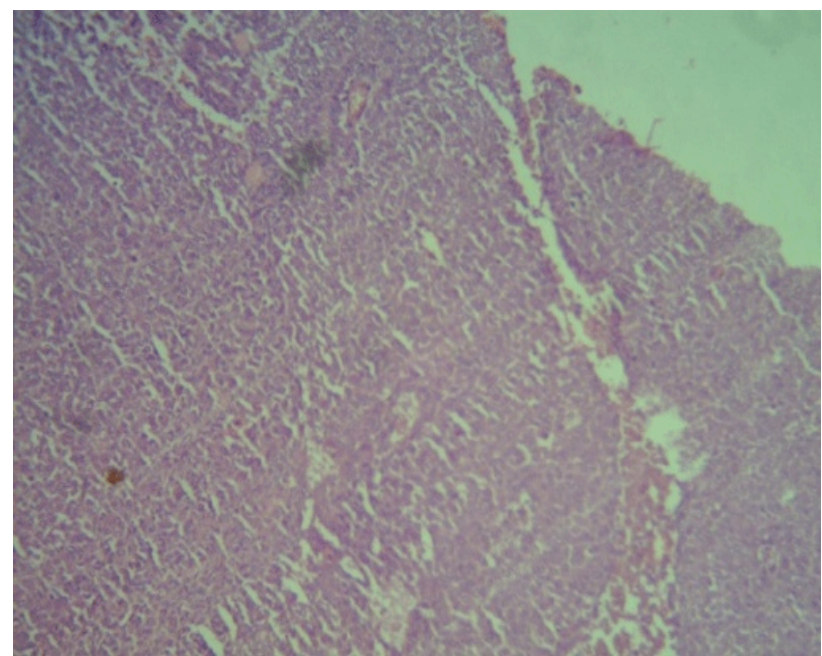

Figure 1: Light microscopy showing dermal appendage (acrospiroma) (magnification, $\times 10$ )

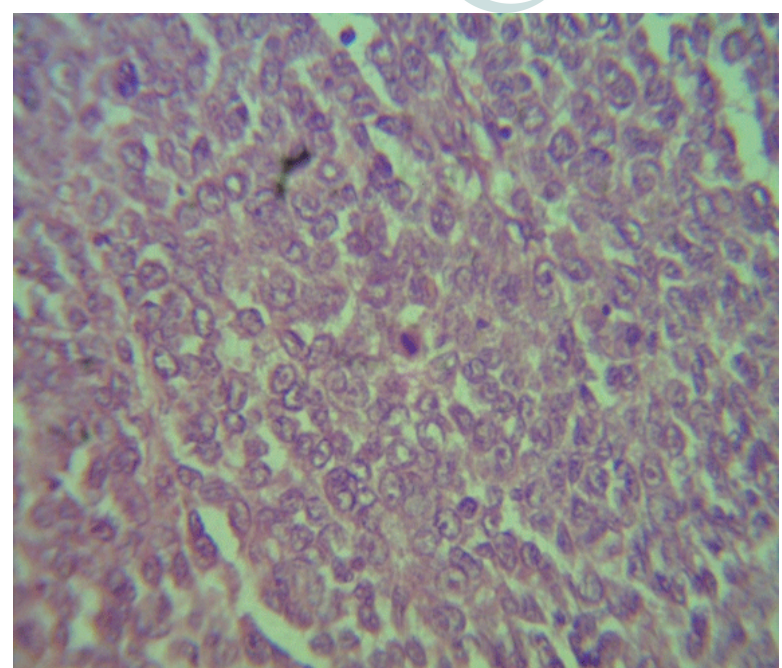

Figure 2: High power view of malignant acrospiroma (magnification, $\times 100$ )

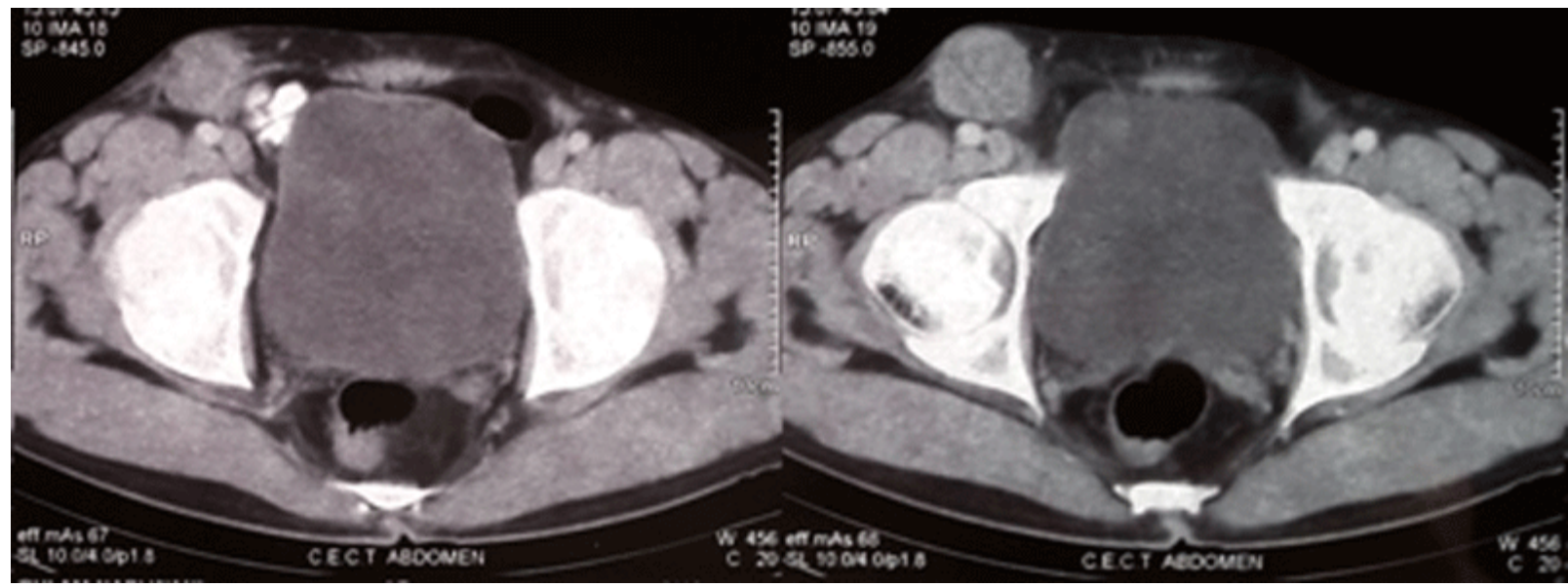

Figure 3: Computed tomography pelvis showing nodal mass involving right inguinal region

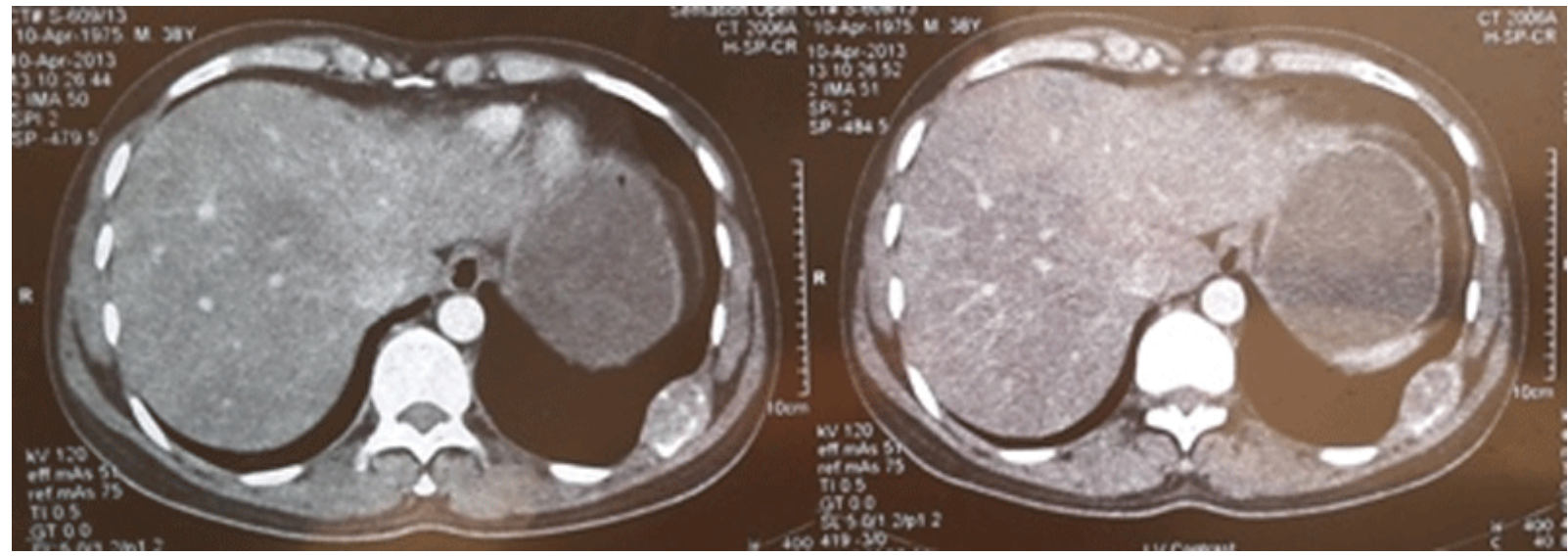

Figure 4: Computed tomography chest showing destructive lesion involving posterior end of 9th rib

FNAC smears of right inguinal mass revealed features of metastatic deposits from a round cell tumor. Immunohistochemistry on the cell block showed strong positivity for vimentin, focal positivity for NSE, and negative staining for desmin, MIC-2, and synaptophysin such features favouring a diagnosis of malignant acrospiroma.

The patient went to surgery and a right inguinal dissection with excision of the mass was done. Grossly, the specimen revealed a fibro-fatty, globular, soft tissue lesion measuring
$15 \mathrm{~cm} \times 8 \mathrm{~cm} \times 6 \mathrm{~cm}$. On serial sectioning a globular, encapsulated grey-white area measuring $5 \mathrm{~cm} \times 5 \mathrm{~cm}$ was identified, with 6 nodes being removed. Microscopic examination again revealed a metastatic cutaneous adnexal tumor (malignant acrospiroma) with 2 of 6 nodes involved.

In view of only a locoregional recurrence, the patient was planned for external beam radiotherapy to right inguinal region with a total of 45 Gy in 20 factions. However, after 13 treatment days, the patient developed ulceration of local site and further radiotherapy was withheld. The 
patient was lost to follow-up but and presented 1 year later, again with a firm nodule at the right inguinal region measuring $1 \mathrm{~cm} \times 1 \mathrm{~cm}$. Repeat CT of chest/abdomen/ pelvis revealed a soft tissue thickening with a solitary, round lesion in the right inguinal region along with an expansile soft tissue density lesion with bone erosion involving the left 9 th rib, suggestive of metastases [Figure 4].

Patient was again subjected to wide local excision of right inguinal lesion and also of 9th rib mass. Three nodes also were dissected, with the largest measuring $3 \mathrm{~cm} \times 3 \mathrm{~cm}$, along with a $4 \mathrm{~cm} \times 5 \mathrm{~cm}$ mass present over and adherent to 9 th rib postero-laterally. Microscopy revealed sections from both the rib lesions as well as groin nodes showing infiltration by malignant sweat gland tumor. Marrow of rib bone revealed infiltration of same tumor. Bilateral iliac bone marrow aspiration and biopsy were negative for tumor.

Patient was subsequently given adjuvant chemotherapy consisting of paclitaxel $175 \mathrm{mg} / \mathrm{m}^{2}$ and cisplatin $80 \mathrm{mg} / \mathrm{m}^{2}$ every 3 weeks for 6 cycles. The patient is on regular follow up and in clinical remission for the past 18 months.

\section{DISCUSSION}

Acrospiromas are cutaneous tumors of sweat duct origin and differentiation. They usually present as slowly enlarging $1 \mathrm{~cm}$ to $2 \mathrm{~cm}$ nodules in middle-aged or older adults without site predilection. The term eccrine acrospiroma was first coined by Johnson and Hewig, in 1969, because, by histologic and histochemical studies, the cells were believed to mimic those of the eccrine sweat gland. ${ }^{[4]}$ Histologically, these lesions are subclassified according to the location of the tumor in relation to the epidermis, with those confined primarily to epidermis as epidermal acrospiroma and those involving both epidermis and dermis as juxtaepidermal acrospiroma or just eccrine poroma. Those which are confined exclusively to dermis or have minimal connection to epidermis are terme dermal acrospiroma or hidradenoma. ${ }^{[1]}$

Malignant acrospiroma comprises a group of rare epidermal, juxtaepidermal, and dermal ductal carcinomas occurring over the head and neck, anterior trunk, or extremities. ${ }^{[5,6]}$ One series described an incidence of only five cases in a group of 750,000 evaluated individuals over an eight-year period. ${ }^{[7]}$ They follow a predictable pattern from the initial tumor site to regional lymph node and ultimately to systemic spread. ${ }^{[3,8]}$

In the present case, the lesion recurred multiple times despite initial wide local excision and adjuvant radiotherapy, carried out following the first recurrence. Secondly, the lesions were slowly growing with delayed recurrent nodal and bone metastases and hence the need for prolonged follow up.

Malignant acrospiromas are treated by wide local excision, but with a local recurrence rate of around $50 \%$. ${ }^{[9]}$
In one case there was described the use of wide local excision with adjuvant radiotherapy for malignant eccrine acrospiroma of the scalp and left parotid, which eventually had local recurrence in the parotid region after 2 years. ${ }^{[3]}$ In another case there was described a more radical surgical approach of amputation of the leg with regional lymph node dissection. This was required for clinical control of extremity acrospiroma. ${ }^{[10]}$ In another reported case, a 66-year-old female with a recurrent malignant acrospiroma of the chest treated by wide radical resection, including chest wall excision, followed by reconstructive surgery and radiotherapy. After 16 months, there was no evidence of local recurrence or distant metastasis. ${ }^{[11]}$

One group described the role of radiotherapy in malignant eccrine acrospiroma, wherein 3 cases of malignant acrospiroma were treated with postoperative radiotherapy with doses of 71-76 Gy to the primary surgical bed and 50 Gy to the draining lymph node basin, with modest disease-free survival ( 27 and 35 months) in 2 of the 3 cases. They suggested that certain histological features such as dermal lymphatic invasion, nerve sheath involvement, deep structural infiltration, positive resected margins, and extracapsular lymph node extension may identify a high risk of recurrence and merit postoperative radiotherapy. ${ }^{[12]}$ The role of chemotherapy in eccrine sweat gland carcinomas, and especially malignant acrospiromas, is not clear. Various case reports and case series have reported on the use of a multitude of drugs in various sweat gland carcinomas including cyclophosphamide and doxorubicin, bleomycin, cisplatin, mitomycin $\mathrm{C}$, with partial response and a median duration of response of 4 to 16 months. ${ }^{[13-16]}$ There are also isolated reports of response to taxanes (docetaxel and paclitaxel). ${ }^{[17]}$

Analyzing all the available literature, we conclude that wide local excision is the treatment of choice for these rare skin appendage tumors when localized, while adjuvant radiotherapy may provide some additional benefit in local control. Poly-chemotherapy is thought to be an option for more extensive lesions and paclitaxel-containing regimens could provide a viable option for palliation. However, more evidence in the form of case series and case reports is needed to establish its usefulness.

\section{Financial support and sponsorship Nil.}

\section{Conflicts of interest}

There are no conflicts of interest.

\section{REFERENCES}

1. Fletcher CD. Diagnostic histopathology of tumors. 3rd ed. Philadelphia: Churchill Livingstone; 2000. p.1457-8.

2. Obaidat NA, Alsaad KO, Ghazarian D. Skin adnexal neoplasms -part 2: an approach to tumours of cutaneous sweat glands. J Clin Pathol 2007;60:45-159.

3. Holden B, Colome-Grimmer M, Savage C, Stierman K, Pou AM. Malignant eccrine acrospiroma with metastases to the parotid. Ear Nose Throat J 2002;81:352-5.

4. Johnson BL Jr, Helwig EB. Eccine acrospiroma. A clinic-pathologic 
study. Cancer 1969;23:641-57.

5. Cooper PH. Carcinomas of sweat glands. Pathol Anпи 1987;22:83-124.

6. Santa Cruz DJ. Sweat gland carcinomas: a comprehensive review. Semin Diagn Pathol 1987;4:38-74.

7. Abenoza S, Ackerman AB. Neoplasms with eccrine differentiation. Philadelphia: Lea and Febiger; 1990. p.415-31.

8. Galadari E, Mehregan AH, Lee KC. Malignant transformation of eccrine tumours. J Cutan Pathol 1987;14:15-22.

9. Wilson KM, Jubert AV, Joseph JI. Sweat gland carcinoma of the hand (malignant acrospiroma). J Hand Surg Am 1989;14:531-5.

10. Headington JT, Niederhuber JE, Beals TF. Malignant clear cell acrospiroma. Cancer 1978;41:641-7.

11. Long WP, Dupin C, Levine EA. Recurrent malignant acrospiroma. Treatment by chest wall excision. Dermatol Surg 1998;24:908-12.

12. Harari PM, Shimm DS, Bangert JL, Cassady JR. The role of radiotherapy in the treatment of malignant sweat gland neoplasms.
Cancer 1990;65:1737-40.

13. Coonley CJ, Schauer P, Kelsen DP, Sordillo P, Huvos AG. Chemotherapy of metastatic sweat gland carcinoma. A retrospective review. Am J Clin Oncol 1985;8:307-11.

14. Briscoe KE, Grage T, Kennedy BJ. Sustained complete remission of metastatic sweat gland carcinoma following regional hyperthermic perfusion. JAMA 1978;240:51-2.

15. Piedbois P, Breau JL, Morere JF, Isreal L. Sweat gland carcinoma with bone and visceral metastases. Prolonged complete remission lasting 16 months as a result of chemotherapy. Cancer 1987;60:170-2.

16. Bandyopadhyay A1, Das M, Jana S, Das A. Malignant acrospiroma of chest and abdominal wall treated with chemotherapy. Indian $J$ Dermatol 2013;58:241.

17. De Iuliis F, Amoroso L, Taglieri L, Vendittozzi S, Blasi L, Salerno G, Lanza R, Scarpa S. Chemotherapy of rare skin adnexal tumors: a review of literature. Anticancer Res 2014;34:5263-8. 